\title{
Tropical Pitcher Plant (NePEnthes: NePenthaceAe) Pollen Germinability and StORAGE: CONSERVATION IMPLICATIONS
}

JAMES C. COKENDOLPHER - Natural Science Research Laboratory, Museum of Texas Tech University, and Department of Biological Sciences, TTU• Lubbock, Texas $79409 \cdot$ USA • cokendolpher@aol.com

Keywords: conservation: Nepenthes - cultivation: Nepenthes, pollination.

\section{Introduction}

Numerous Nepenthes species are at risk of extinction in the wild, with a dozen being on the IUCN Red List as "Critically Endangered" or "Endangered" (von Arx, et al. 2001; IUCN, 2003). The principal threats to wild Nepenthes are habitat destruction and in some cases the removal of plants by collectors (Clarke, 2001). Therefore, ex situ conservation measures should be implemented. Being able to quickly determine the viability of pollen and to store it until a female plant is blooming (Nepenthes are dioecious) will greatly enhance the chances of obtaining seeds and the next generation of plants.

In order to better understand options available for $e x$ situ production of seeds, studies were undertaken to better define methods for collection and viability testing of pollen of Nepenthes ampullaria, $N$. tentaculata, and $N$. ventricosa. Methods for storage of pollen of a model species $N$. ventricosa were compared. Although the results discussed are preliminary, they give us a glimpse of what is possible and some recommendations for prolonged storage are made.

Beyond the pollen collection, storage, and pollen/stigma interactions; matters that concern pollen vigor and ultimate survival of a species in a maintenance program are issues of genetics and environment of the parent plants. Haphazardly collecting, storing, and placing pollen in an ex situ conservation program will ultimately result in a waste of time and materials with the possible extinction of the targeted plant species. Storage of pollen for prolonged periods (decades) seems feasible and should be started while pollen of the maximal number of individual plants are still available.

\section{Methods}

The hanging drop method involves the germination of pollen grains in a table sugar (sucrose) solution, as described for orchid pollen by Light \& MacConaill (1996): pollen grains are placed on a hanging droplet of sugar solution suspended from the lid of an enclosed transparent surface such as a Petri dish. The pollen germination can be observed with a microscope from above. No wetting agent is used and many of the grains will remain on the lower surface of the hanging drop.

Fresh dilutions should be used because microorganisms rapidly populate sugar solutions retained at room temperatures. Alternately, aliquots may be prepared and frozen for later use.

Experimentation may be required to determine the correct droplet size to prevent drops from running when the lid is inverted, or evaporating before tube growth can be observed. Humidity within the closed Petri dish is maintained by adding water to the bottom of the dish. Several replicates of each test should be used so that failures due to bacterial/fungal contamination or drops falling during lid placement will not require replication of a test. The area where the dishes are placed should be of constant temperature, or water will condense on the lid of the Petri dish diluting the sugar solution.

Although the pollen and tubes can be detected at 40X, the morphology is difficult to discern and any contaminating fungal bodies can be mistaken for tubes. Transmitted light microscopy with a compound microscope at $100 \mathrm{X}$ is ideal for rapid scanning of the Petri dishes. 
Pollen viability means the ability of pollen grains to germinate on the stigma of a receptive flower, resulting in pollination and production of germinable seed (Dafni \& Firmage, 2000; Firmage \& Dafni, 2001, and citations therein). Unfortunately, measuring viability by seed set in Nepenthes is difficult and time consuming. The development of the fruit capsule generally takes 3-6 months (Clarke, 1997, 2001) and germination of the seeds can often take several additional months. Most indirect methods to assess pollen viability rely on stains which are reported to only dye living tissue. Several of these tests are not reproducible whereas others have been demonstrated to stain dead pollen. Further, many of the chemicals needed for these procedures could potentially be difficult to obtain in some parts of the world. This latter potential problem is especially important when such methods are needed for testing pollen in remote situations. A particularly promising method involves the germination of pollen grains in a table sugar (sucrose) solution.

Pollen germination (production of pollen tubes) occurs at room temperatures often within 12 hours. Longer periods are needed for some pollen but anything beyond 36 hours suggests problems with the pollen. The first stage of germination is the production of finger-like tubes from the pollen grain. The tube will elongate in a few hours and become tangled in nearby pollen tubes. Germinated grains with pollen tubes are depicted in Figures 1-4. Early stages of fungal growth appear similar to pollen tubes but fungi have multi-branched tips (Figure 5).

The hanging drop method only requires a very minute amount of pollen to test germinability, but the pollen should be well mixed so a representative sample is used. Enough pollen will adhere to the point of a pin or probe for a drop of sugar solution. If germination percentages are to be recorded, the number of grains per drop should be reduced and the grains germinating should be counted before they become tangled (Figures 1-2 are examples of over-grown/crowded preparations). In addition to the percent of grains germinating, any deformed grains or pollen tubes should be noted as these could signal future pollination problems.

Pollen of Nepenthes ventricosa germinated in 0.4-0.9 M sucrose, but $0.6 \mathrm{M}$ solution was optimal. Nepenthes ampullaria germinated in $0.6 \mathrm{M}$ whereas $N$. tentaculata did not; sufficient pollen of
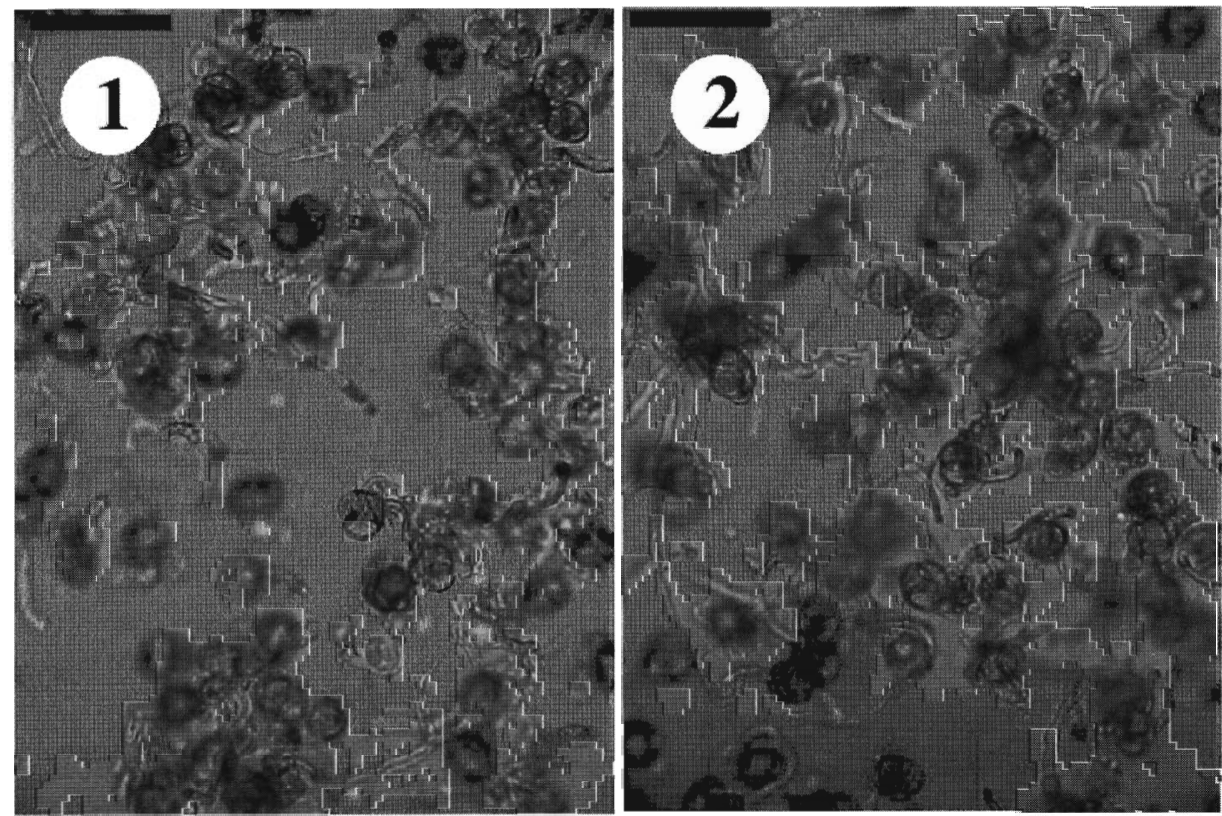

Figures 1: Nepenthes ventricosa pollen in 0.6 Figure 2: Nepenthes ventricosa pollen in 0.6 $M$ sugar solution, harvested from freshly $M$ sugar solution, harvested from flowers opened flowers where nectar and pollen are that have opened a few days previously. actively being produced. Scale bar $=0.1 \mathrm{~mm}$. Scale bar $=0.1 \mathrm{~mm}$. 
these two species was unavailable for testing at other sucrose concentrations. (The N. tentaculata pollen was at least partially viable as a portion was successfully used to pollinate another plant, as described below.) When testing other species it is suggested to use a series of sucrose dilutions (0.1 to $0.9 \mathrm{M}$ ) to determine which is optimal for that species.

While germinating the Nepenthes ampullaria and $N$. ventricosa pollen, illumination was held constant at about 30000 lux ( $3000 \mathrm{fc}$; from a 75 watt incandescent light at $25 \mathrm{~cm}$ ). When pollen was placed in $0.6 \mathrm{M}$ sugar solution (an optimal dilution) but kept in the dark for 48 hours, no tubes were seen. The dish was placed under illumination (40 watt light at $25 \mathrm{~cm}$ ), and tubes were observable within an additional 48 hours. While the pollen of Nepenthes ampullaria and N. ventricosa would not germinate in dark or low light conditions, initial tests for other species should be run in both dark and light situations.

\section{Diurnal Variation in Pollen Viability}

Male and female Nepenthes flowers are small but are easily distinguished by close examination of the external morphology. Illustrations of these differences are available in numerous publications, including those by Clarke (1997: Figure 6), Kurata (1976: Figure 4, plate 25), and Pietropaolo \& Pietropaolo (1986: Figures 3-12). Flowers of both sexes lack petals but have four, slightly cup-shaped sepals with numerous large nectar glands. Female flowers have the much fatter ovary (often as wide as long) with the white to yellowish to pink colored stigma on top. The flowers open slowly and remain open with the sepals reflexing over time until they wither and dry.

Although Nepenthes hybrids have been artificially created in hothouses since the mid-1800s, pollination has been little studied (but see Chua, cited in Clarke, 2001; Frazier, 2000; Frazier, in Clarke, 2001; Kato, 1993; Kaul, 1982; Moran, 1993). These researchers have found a number of potential pollinators, such as flies, moths, beetles, wasps, etc., and that some species may be pollinated during the day, while others may be pollinated at night or during both times. With the large habitat diversity in the genus Nepenthes, pollen production and viability data obtained from one or a few species should not be applied to all members of the genus. Further testing will be needed to better define conditions for pollination in each potentially endangered Nepenthes species.

Flowering of $N$. ventricosa was studied in a greenhouse. This species produced nectar in the late evening and night which would dry during the early hours of daylight. It had a very strong and distinctive foul smell during the night. The nectar is attractive to Dolichoderinae ants and fruitflies which were seen on the Nepenthes inflorescences in the same greenhouse. This indicates that female Nepenthes flowers should be isolated if any male Nepenthes are concurrently flowering in the same greenhouse.

Pollen was collected from $N$. ventricosa for two days by tapping the entire inflorescence over a piece of wax paper and then rolling the end of the paper to form a funnel so that the pollen could be shaken into a plastic microtube (cryotubes suitable for storage in liquid nitrogen). Pollen collected at the first sampling of several different inflorescences revealed large numbers of non-viable pollen grains. This suggests that pollen should be removed prior to any collection to verify that older pollen was not left on the inflorescence. This is especially important in a greenhouse where insect pollinators and high winds are not usually present.

Pollen was collected at the end of each period: 8-11 AM, 11 AM-12:30 PM, 12:30-3.30 PM, 3:30-8 PM, 8-10 PM, 10 PM-12 AM, 12 AM-8 AM. Viability of pollen collected during the night (10 PM-8 AM) was excellent with virtually $100 \%$ of the grains forming tubes. In significant contrast, only $2.6-5.0 \%$ of the grains collected during the day (8 AM to $10 \mathrm{PM}$ ) showed tubes from pollen.

This pilot experiment demonstrated in this species that peak periods of odor and nectar production correspond with the release of viable pollen. It also demonstrated that most pollen collected during the daylight hours was either dead or in some form of stasis such that it would not produce pollen tubes under the standard conditions listed earlier. This reduced vigor has not been reported for Nepenthes, even among hybridizers. The reason this has not been noted may be because even $5 \%$ viable pollen will result in sufficient seed set if many thousands of grains are transferred during pollination. It is interesting to note that pollen of this species requires light in order to germinate, but peak pollen viability is apparently during the night. 
Pollen of some plants (including the carnivorous plant genus Pinguicula; pers. com. M. Studnicka 2004) is completely developed in very young anthers, prior to dehiscence. So, viable pollen waits for some time to be released in these plants. An interesting follow-up study would be to determine if mature pollen enclosed in undehisced anthers are viable at all points in the diurnal cycle.

\section{Storage}

In the early 1800 s Nepenthes hybridizers stored pollen at room temperatures and were only able to keep it viable for a few days. More recently individuals have attempted storage by keeping pollen at reduced temperatures. Slack (1986) stated that pollen could be stored in the main compartment of the home refrigerator for "some" weeks. Pietropaolo \& Pietropaolo (1986) stated that pollen stored well under refrigeration $\left(3^{\circ} \mathrm{C} / 38^{\circ} \mathrm{F}\right)$, surviving for "at least one year in all species of which we are aware." They also provided a methodology for drying and freezing pollen for Gloxinia, but stated at that time no one had tried it on any carnivorous plants. D'Amato (1998) apparently was the first to report that pollen of such species could be stored for up to one year in foil packets in the home freezer. Clarke (2001) also stated that pollen can be stored for "several weeks in a freezer before use." Unfortunately, none of these authors provided precise details on how they treated the pollen before freezing. Presumably, all their results are based upon production of seeds as a measure of viability because they mention no other means of testing.

Different storage methods were investigated, to learn more about the factors important in reducing stored Nepenthes pollen viability. Nepenthes ventricosa pollen collected during the night was stored for differing durations in the dark at: room temperature $\left(20-22^{\circ} \mathrm{C} / 68-72^{\circ} \mathrm{F}\right)$, home refrigerator (about $3-4^{\circ} \mathrm{C} / 37-39^{\circ} \mathrm{F}$ ), and home freezer (about $-18^{\circ} \mathrm{C} / 0^{\circ} \mathrm{F}$ ). Tests were performed under four sets of conditions: open vial in sealed larger jar with desiccant (approaching 0\%R.H.), sealed vial with pollen in water, sealed vial dried to room humidity (approximately $40 \%$ R.H.), open vial in sealed larger jar with a slurry of calcium chloride (30\%R.H). Room temperature stored pollen was air dried in an atmosphere of approximately 40-50\%R.H.

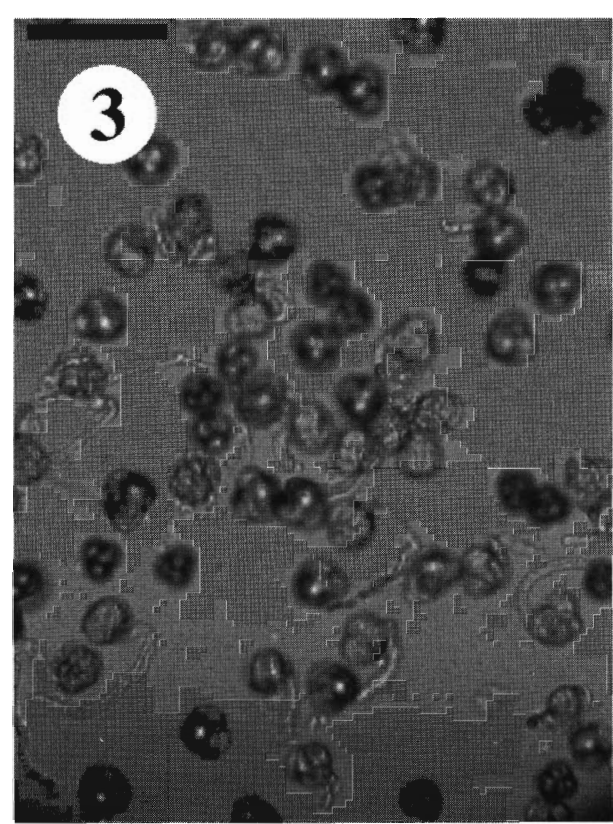

Figure 3: Nepenthes ventricosa pollen in 0.6 $\mathrm{M}$ sugar solution, harvested from old flowers lacking nectar production, and with sepals that are reflexed. Scale bar $=0.1 \mathrm{~mm}$.

After three days of storage, germination of pollen stored at room temperature was drastically reduced. By the 8 th day only 10 pollen tubes could be located out of thousands of grains tested. Pollen stored in water for one week showed very low germination whereas the drier samples appeared unaltered. By the end of six months all samples showed good growth except for those at room temperature and those in water.

At the end of six months, samples stored in the refrigerator were split and transferred to a laboratory ultracold freezer at $-80^{\circ} \mathrm{C} /-112^{\circ} \mathrm{F}$ and to liquid nitrogen at $-196^{\circ} \mathrm{C} /-320^{\circ} \mathrm{F}$. These latter conditions were only short-term to verify that such conditions would not fracture or otherwise harm the pollen. Samples previously maintained at humidities of $0-40 \%$ R.H. that were held at $196^{\circ} \mathrm{C}$ for 20 hours and $-80^{\circ} \mathrm{C}$ for over a month showed no noticeable reduction in germination. At the end of 10 months storage at $-18^{\circ} \mathrm{C}$, pollen showed a great reduction in germination. Those dried before storage showed the most activity, but still only about $40 \%$ of the pollen was active. The other samples showed no germination, except for two samples that had been air dried to approximately $40 \%$ R.H. and stored at $-18^{\circ} \mathrm{C}$. 
These latter two samples had 0.15 to $5 \%$ germination after 24 hours. The early death of this pollen may also have been influenced by the repeated freezing and thawing that samples underwent with multiple extractions of pollen samples for test and attempted pollinations. Drying and continuous ultracold conditions $\left(-80^{\circ} \mathrm{C}\right.$ and below) appear to be the best method for storing Nepenthes pollen for extended periods.

Nepenthes ventricosa pollen that had been frozen in liquid nitrogen (20 hours) and the remainder of six months at $-18^{\circ} \mathrm{C}$ was used to pollinate a female $N$. khasiana. The resulting hybrid seed had a relatively good germination, but somewhat slow; the first dozen seedlings were only visible after three months.

Pollen intended for prolonged storage should be shipped on dry-ice, or minimally with ice packs in as fast a transport as possible. Because all Nepenthes are CITES listed (Appendix I and II), shipping rapidly between countries may be somewhat complicated.

\section{Conservation Implications}

The convention used in the past for greenhouse pollination of carnivorous plants (especially for production of hybrids in the genus Nepenthes) was to pollinate heavily and often. While this method ensures good seed set (if the pollen is viable) it requires more pollen than might be available for endangered plants. Poor quality pollen or incorrect placement of the pollen will result in the waste of receptive stigmas and pollen.

Optimal temperatures for growing lowland Nepenthes plants may be relatively high and constant $\left(21-29^{\circ} \mathrm{C} / 70-85^{\circ} \mathrm{F}\right)$, whereas those of the highland plants are lower with a nocturnal drop (10$21^{\circ} \mathrm{C} / 50-70^{\circ} \mathrm{F}$ ). As discussed above, pollen of $N$. ventricosa (an intermediate species kept in highland conditions) is very short lived when left on the plant. High humidity/moisture and light are likely to be important in limiting pollen viability. Pollen placed on a female stigma at the wrong time of day will be exposed to those deleterious conditions until the stigma is more active (perhaps the next night or day). In the wild, pollination of Nepenthes is thought to be primarily by insects because the flowers secrete nectar that is attractive to insects and the pollen is released in relatively large tetrads with echinate sculpturing (Kato, 1993, and citations therein). In order to achieve maximal seed set, healthy active pollen must be used when the stigma is receptive. Unless receptivity data for each species suggest otherwise, it is probably best to place pollen on stigmas surrounded by sepals that are secreting nectar and a scent; thus, mimicking insect pollinator activity. Experiments should be conducted to better define receptivity periods based on morphology of the sepals (erect versus reflexed) and nectar production so that growers can be prepared to attempt pollination during the most ideal conditions. Dafni \& Motte Maués (1998) have developed a rapid and relatively simple procedure for determining stigma receptivity (involving detection of enzymatic activity). This

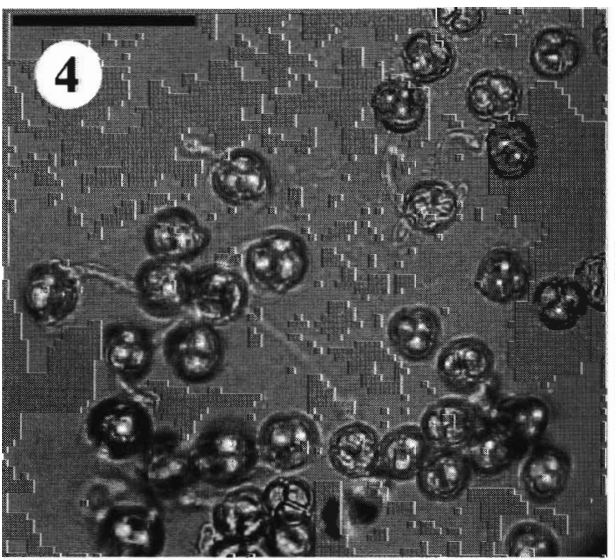

Figure 4: Nepenthes ampullaria pollen with tubes in 0.6 M sugar solution following storage at $-80^{\circ} \mathrm{C}$ for six months. Scale bar $=0.1 \mathrm{~mm}$.

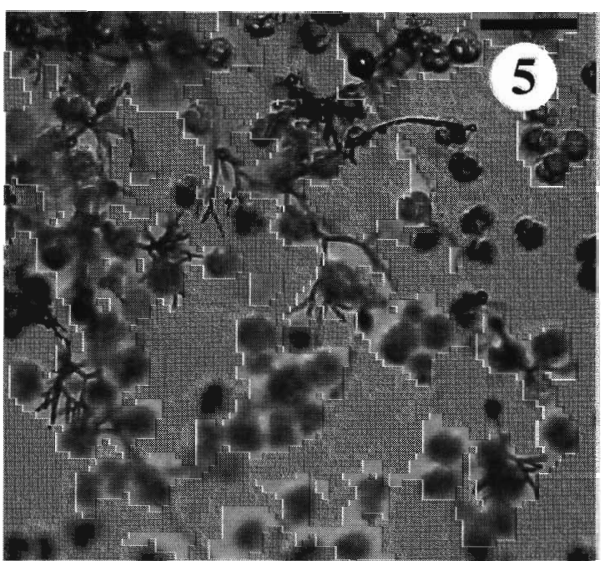

Figure 5: Contaminated sample showing multi-tipped fungal growth among Nepenthes ampullaria pollen grains. Scale bar $=0.1 \mathrm{~mm}$. 
method however is destructive to the stigmas tested.

Pollen should be collected from the entire inflorescence by tapping it over wax paper. This should be done at the beginning of any nectar/scent production (to remove old pollen) and at the end of the day/night period to collect the most active pollen. Some experimentation on collection will be needed with species that produce large amounts of nectar because the nectar tends to trap the pollen. If necessary, anthers covered in pollen can be detached with dissection tools and collected directly into tubes. Percentage of pollen activity or quality should be determined prior to any long-term storage, so that time, supplies, and effort will not be wasted on low quality or dead pollen. Because varying humidities below $40 \%$ did not appear to alter the germinability of the pollen that was stored for less than six months, but did for longer periods, it is suggested that pollen be dried with a desiccant. It is also much easier to obtain and maintain this low humidity outside of the laboratory and previous studies with pollens and seeds of other species found drier conditions best. Pollen should be stored at the lowest temperature available. Flash freezing and rapid thawing from liquid nitrogen does not appear to alter the viability of relatively dry Nepenthes pollen. If large quantities of pollen are collected (or collected over several days), it should be split into several tubes so that opening one tube will not require thawing of all the pollen. A portion of all male flowerings of endangered Nepenthes species should be banked at an institution capable of storage at $-80^{\circ} \mathrm{C}$ or below. This pollen can then possibly be used years later if genetic contamination (hybrids) or a reduction in genetic diversity is discovered in the remaining plants.

\section{Acknowledgements}

Meredith Griffith (Leach Botanical Garden, Portland), Steve LaWarre (Frederik Meijer Gardens \& Sculpture Park, Grand Rapids), Travis H. Wyman (Emory University) are thanked for providing some of the pollen examined during this study. A $-80^{\circ} \mathrm{C}$ freezer, dewar, and liquid nitrogen were provided by Drs. Robert Baker and Richard Monk of the Molecular Resources Collection, Natural Science Research Laboratory, Museum of Texas Tech University. I am also grateful to Aaron J. Hicks (Orchid Seedbank Project, Chandler, Arizona) and Marilyn Light (University of Ottawa) for discussions on pollen. Dr. Light's words of encouragement and suggestions were especially appreciated after my initially failed attempts with pollen germination. I am thankful for the valuable comments on various drafts of the manuscript by Mr. Hicks, Drs. Gad Perry (Department of Range, Wildlife and Fisheries Management, Texas Tech University), Miloslav Studnicka (Botanic Gardens Liberec, Czech Republic), and both editors of this journal.

\section{References:}

Clarke, C. 1997. Nepenthes of Borneo. Natural History Publications, Kota Kinabalu, Sabah, 207 pp. Clarke, C. 2001. Nepenthes of Sumatra and Peninsular Malaysia. Natural History Publications, Kota Kinabalu, Sabah, 326 pp.

Dafni, A. and Firmage, D. 2000. Pollen viability and longevity: practical, ecological and evolutionary implications. Plant Systematics and Evolution, 222:113-132.

Dafni, A. and Motte Maués, M. 1998. A rapid and simple procedure to determine stigma receptivity. Sexual Plant Reproduction, 11:177-180.

D'Amato, P. 1998. The savage garden: cultivating carnivorous plants. Ten Speed Press, Berkeley, $314 \mathrm{pp}$.

Firmage, D.H. and Dafni, A. 2001. Field tests for pollen viability; a comparative approach. Acta Horticulturae, 561:87-94.

Frazier, C.K. 2000. Pollination and reproductive ecology of three lowland tropical pitcher plants (Nepenthes) and their hybrids. Abstracts, International Carnivorous Plant Society, World Congress, San Francisco. Available at: http://www.carnivorousplants.org/news/ meeting2000/Frazier.htm

IUCN 2003. 2003 IUCN Red List of Threatened Species. <www.redlist.org>. Downloaded on 08 August 2004.

Kato, M., 1993, Floral biology of Nepenthes gracilis (Nepenthaceae) in Sumatra. American Journal of Botany, 80(8):924-927. 
Kaul, R.B., 1982. Floral and fruit morphology of Nepenthes lowii and N. villosa, montane carnivores of Borneo. American Journal of Botany, 69(5):793-803.

Kurata, S. 1976. Nepenthes of Mount Kinabalu. Sabah National Parks Trustees, Kota Kinabalu, 80 pp.

Light, M.H.S. and MacConaill, M. 1996. Reproductive constraints in Cypripedium: horticultural and conservation viewpoints. Pp. 77-90 in: North American Native Terrestrial Orchids Conference. Propagation and Production. Germantown, Maryland.

Moran, J.A., 1993. Visitors to the flower of the pitcher plant Nepenthes rafflesiana. Brunei Museum Journal, 8:73-75.

Pietropaolo, J. and Pietropaolo, P. 1986. Carnivorous plants of the world. Timber Press, Inc., Portland, $206 \mathrm{pp}$.

Slack, A. 1986. Insect-eating plants \& how to grow them. University of Washington Press, Seattle, $172 \mathrm{pp}$.

von Arx, B., Schlauer, J. and Groves, M. 2001. CITES Carnivorous Plant Checklist. Royal Botanic Gardens, Kew, United Kingdom. 101 pp.

\section{NAMES OF CULTIVARS REGISTERED IN 2005}

Sarracenia 'Leah Wilkerson', B.Garcia, Carniv.Pl.Newslett. 34:27 (2005), 10 Oct. Sarracenia 'Melissa Mazur', P.Wilson, Carniv.Pl.Soc.J.(UK) 27:42 (2005), 14 Nov. Sarracenia 'Victoria Morely', S.Morely, Carniv.P1.Soc.J.(UK) 27:15 (2005), 14 Nov. Dionaea 'Green Dragon', M.Erbacher \& M.Stoeckl, Taublatt 51:25 (2005), 24 Nov. Dionaea 'Holland Red', M.Erbacher \& M.Stoeckl, Taublatt 51:21 (2005), 24 Nov. Dionaea 'Red Burgundy', M.Erbacher \& M.Stoeckl, Taublatt 51:22 (2005), 24 Nov. Utricularia 'Betty's Bay', S.Morely, Carniv.Pl.Soc.J.(UK) 27:33 (2005), 14 Nov.

Utricularia 'Jitka', M.Studnicka, Carniv.Pl.Newslett. 34:27 (2005), 10 Oct.

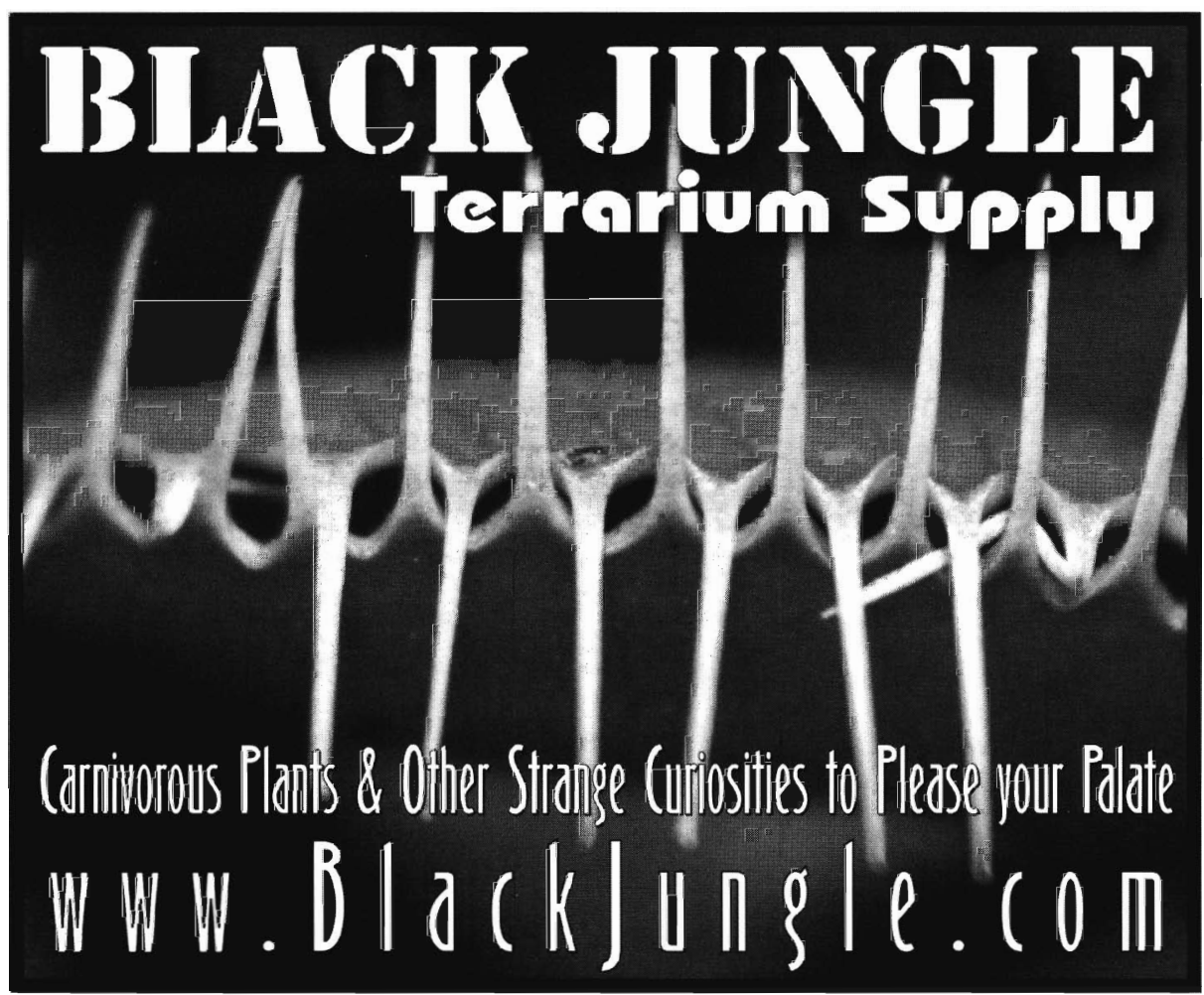

